Article

\title{
Biogenic Nanosilica Synthesis Employing Agro-Waste Rice Straw and Its Application Study in Photocatalytic Degradation of Cationic Dye
}

\author{
Garima Singh ${ }^{1}$, Hossein Beidaghy Dizaji ${ }^{2,3} \mathbb{D}$, Hariprasad Puttuswamy ${ }^{1}$ and Satyawati Sharma ${ }^{1, *(D)}$ \\ 1 Centre for Rural Development and Technology, Indian Institute of Technology, New Delhi 110016, India; \\ dpgarima@gmail.com (G.S.); phari@iitd.ac.in (H.P.) \\ 2 DBFZ Deutsches Biomasseforschungszentrum Gemeinnützige GmbH, Torgauer Straße 116, \\ 04347 Leipzig, Germany; hossein.beidaghy@dbfz.de \\ 3 Institute of Chemical Technology, Leipzig University, Linnéstr. 3, 04103 Leipzig, Germany \\ * Correspondence: satyawatis@hotmail.com
}

check for

updates

Citation: Singh, G.; Dizaji, H.B.;

Puttuswamy, H.; Sharma, S. Biogenic Nanosilica Synthesis Employing Agro-Waste Rice Straw and Its Application Study in Photocatalytic Degradation of Cationic Dye.

Sustainability 2022, 14, 539. https:// doi.org/10.3390/su14010539

Academic Editors: Marc A. Rosen and Antoni Sánchez

Received: 25 November 2021

Accepted: 28 December 2021

Published: 4 January 2022

Publisher's Note: MDPI stays neutral with regard to jurisdictional claims in published maps and institutional affiliations.

Copyright: () 2022 by the authors Licensee MDPI, Basel, Switzerland. This article is an open access article distributed under the terms and conditions of the Creative Commons Attribution (CC BY) license (https:// creativecommons.org/licenses/by/ $4.0 /)$.

\begin{abstract}
The current study aims towards a holistic utilization of agro-waste rice straw (RS) to synthesize nanosilica (SiNPs) employing the sol-gel method. The effect of ashing temperature was evaluated for the synthesis process. X-ray diffraction demonstrated a broad spectrum at $21.22^{\circ}$ for SiNPs obtained using RSA-600, signifying its amorphous nature, whereas crystalline SiNPs were synthesized using RSA-900. The EDX and FTIR spectra confirmed the significant peaks of Si and O for amorphous SiNPs, confirming their purity over crystalline SiNPs. FE-SEM and TEM micrographs indicated the spheroid morphology of the SiNPs with an average size of $27.47 \mathrm{~nm}$ (amorphous SiNPs) and $52.79 \mathrm{~nm}$ (crystalline SiNPs). Amorphous SiNPs possessed a high surface area of $226.11 \mathrm{~m}^{2} / \mathrm{g}$ over crystalline SiNPs $\left(84.45 \mathrm{~m}^{2} / \mathrm{g}\right)$. The results obtained attest that the amorphous SiNPs possessed better attributes than crystalline SiNPs, omitting the need to incorporate high temperature. Photocatalytic degradation of methylene blue using SiNPs reflected that $66.26 \%$ of the dye was degraded in the first $10 \mathrm{~min}$. The degradation study showed first-order kinetics with a half-life of $6.79 \mathrm{~min}$. The cost-effective and environmentally friendly process offers a sustainable route to meet the increasing demand for SiNPs in industrial sectors. The study proposes a sustainable solution to stubble burning, intending towards zero waste generation, bioeconomy, and achieving the Sustainable Development Goals (SDGs), namely SDG 13(Climate Action), SDG 3(Good health and well-being), SDG 7(use of crop residues in industrial sectors) and SDG 8 (employment generation).
\end{abstract}

Keywords: rice straw; ash; nanosilica; methylene blue; zero waste generation; decolorization; SDGs

\section{Introduction}

Rice straw (RS), lignocellulosic biomass, is a very common agro-waste generated in the agriculture system after the post-harvesting of rice. Incorporating the crop and harvesting method, approximately $40-60 \%$ of residual biomass comprises RS [1,2]. RS is a stiff, voluminous lignocellulosic biomass with significant silica $\left(\mathrm{SiO}_{2}\right)$ deposits, for which the level of biogenic silica can reach up to $82 \%$ on a dry weight basis. The complex structure limits the usability of RS. Being a quick, easy and cheap process, most farmers opt for open field-burning as the most preferred approach to dispose of RS in agricultural fields $[3,4]$. The burning of farm waste causes the ghastly pollution of soil and water at the regional scale. This practice also adversely reduces the nutrient composition in the soil. The elemental carbon, nitrogen and sulphur become completely burnt and subsequently emit hazardous gases such as methane, nitrogen oxide and ammonia, causing austere atmospheric pollution. These gases also contribute and further add up to the existing ozone pollution. Burning releases fine particles which are known to aggravate chronic heart and lung diseases [3]. 
Rice plants accumulate $\mathrm{Si}$ by polymerizing water-soluble silicic acid $\left(\mathrm{H}_{4} \mathrm{SiO}_{4}\right)$ absorbed from the soil into insoluble polysilicic acids, precipitated as amorphous silica and deposited on the plant cell's exterior $[5,6]$. Si is deposited in plants primarily as phytoliths, which consist of amorphous hydrated silica. These beneficial attributes and the rich Si content of RS make it a suitable alternate source of biogenic nano-silica [7]. The Si can be extracted from RS by ashing at a temperature beyond $400{ }^{\circ} \mathrm{C}$. However, temperature above $700{ }^{\circ} \mathrm{C}$ leads to the production of crystalline $\mathrm{Si}$ such as cristobalite and tridymite, with limited applications, possessing higher risks of silicosis [8-10].

In recent years, many efforts have been made to synthesize silica nanoparticles (SiNPs) from various preparatory materials, precisely chemical and natural sources. Different approaches such as the sol-gel process, chemical precipitation method, microemulsion processing, plasma synthesis, chemical vapor deposition, combustion in a diffusion flame and hydrothermal treatment have been employed for preparing Si-NPs [11,12]. Among these, the sol-gel process, also known as the "Stöber method" is a relatively modest and low-cost process $[13,14]$. It is worth highlighting that the chemical route is not only expensive, but it also adds to the list of pollutants, therefore, adapting a green route is the need of the hour for a healthy and safe environment [15].

The scientific community has successfully utilized the potential of nanotechnology to develop different products and materials at the nanoscale for societal welfare [12,16]. Silica is an important inorganic material with a panoramic range of applications in the textile industry, automobile industry, biology, medicine, adsorbents, drug delivery system, etc. $[11,12,17]$; additionally, it also holds an advantage over conventional precursors owing to its abundancy as well as being a cheap substrate [18].

SiNPs holds potential application in various sectors due to its high surface area and reactivity in broad areas $[12,13,19,20]$. These versatile properties enhance their potentials for developing biosensors and biomarkers, holding application in the detection of plateletderived microparticles and the identification of leukemia cells [21]. The combination of SiNPs with super absorbent polymers helps in assuaging the plastic shrinkage. Additionally, the unique ability of SiNPs to exhibit the nucleation effect and pozzolanic activity leads to a decrease in the setting time and the mitigation of calcium leaching losses for cement-based materials [22,23]. The suitability of SiNPs as fillers in nanosilica composites has also been investigated by Salimian et al. [24]. The unique ability of SiNPs also tends to enhance its catalytic and photocatalytic applicability for removing an organophosphate pesticide, elimination of heavy metals from wastewater, the treatment of textile effluents and dye decolorization $[23,25]$.

Of the various pollutants reported, methylene blue is a prominent blue cationic thiazine dye used widely in textile, paper and wood industries. It is documented that intense exposure to this dye leads to release of aromatic amines with severe environmental and health hazards. In previous years, chemical-based products have been designed to degrade toxic pollutants effectively; yet again, the persistent and non-degradable nature with its known tendency to bioaccumulate serves well as another potential environmental health hazard, demanding an adequate replacement [26,27].

In this regard, nanomaterials have emerged as an influential factor in removing organic pollutants due to their excellent high surface area and adsorption capacity. Exploring the potential of naturally synthesized nanomaterials holds potential utility. With reference to the proposed methods, although silica is inert for many reactions, it shows noticeable catalytic activities under ultraviolet irradiation below $390 \mathrm{~nm}$, e.g., photo-oxidation of $\mathrm{CO}$, photo-metathesis of propene, photo-epoxidation of propene and silica-based photocatalysts such as silica-alumina, silica-alumina-titania and gold-coated $\mathrm{SiO}_{2}$ with practical photocatalytic activities possessing a significant utility in photodegradation of toxic products [27-29]. The utilization of agro-waste-derived SiNPs in the degradation of cationic dye serves as an excellent example of two birds with one stone, on one end promoting a natural route towards the treatment of the toxic effluents while on the other proposing an 
excellent alternative towards the minimization of chemical-based routes for the treatment of organic pollutants.

A dearth of literature highlights the difference observed in the characterization of SiNPs when RS ashing is performed at $900{ }^{\circ} \mathrm{C}$ vs. the ashing temperature of 550 to $600{ }^{\circ} \mathrm{C}$. To this end, a comparative analysis of amorphous and crystalline SiNPs synthesized using the sol-gel method was conducted in the current study to empirically attest the amorphous SiNPs as a preferential choice over crystalline SiNPs. The optimal SiNPS were further explored for a cost-effective route for the removal of the toxic pollutant methylene blue. The study offers insights to researchers and stakeholders towards a sustainable route for the synthesis of SiNPs and its application in the degradation of the toxic cationic dye methylene blue. The increase in the utility of silica-rich RS can serve as an integral factor in avoidance of stubble burning and exploring its utility will provide new ventures towards a suitable replacement to chemical route adopted to eliminate the toxic dyes in industries, thus playing an integral role towards bioeconomy as well as to the safe and healthy environment. The study overall is an attempt to meet the Sustainable Development Goals (SDGs). An alternative to stubble burning will assist in targeting SDG 13 (Climate Action), SDG 3 (Good health and well-being), SDG 7 (Use of crop residues in industrial sectors) and SDG 8 (Employment generation), highlight the aim of the study undertaken [30].

\section{Materials and Methods}

\subsection{Collection of Raw Material and Rice Straw Ash Preparation}

RS was collected from the Khatauli village of Uttar Pradesh, India. Before any treatment, the piled agro-residue was washed thoroughly using distilled water and then dried at $105{ }^{\circ} \mathrm{C}$. Dried RS was chopped into small pieces and pulverized in a supermass collider (Masuko Sangyo Co. Ltd., Kawaguchi, Japan). For uniform size powdered straw, the pulverized material was passed through a 20-mesh screen. The ground RS powder was re-washed to remove any dust particles and dried in a hot air oven at $60{ }^{\circ} \mathrm{C}$. Finally, dried and cleaned straw powder was burned to ashes using a muffle furnace, maintaining the furnace temperature at $600{ }^{\circ} \mathrm{C}$ and $900{ }^{\circ} \mathrm{C}$ for $4 \mathrm{~h}$ leading to grey and white ash production, respectively [12]. The ashes obtained at two different temperatures are denoted hereafter as RSA-600 and RSA-900, used to synthesize SiNPs.

\subsection{Nano Silica Extraction from Rice Straw Ash}

A combined method for extracting nanosilica from RS was performed based on the methodology provided by Bahrami et al. [10] and Kalapathy et al. [31]. A detailed methodology followed is outlined in Figure 1.

\subsection{Characterization of Rice Straw Ash and Nanosilica Powders}

\subsubsection{X-ray Diffraction (XRD)}

The amorphous and crystalline nature of calcinated RSAs and synthesized SiNPs were determined using XRD X'Pert Pro (PANalytical The Netherlands). The samples were

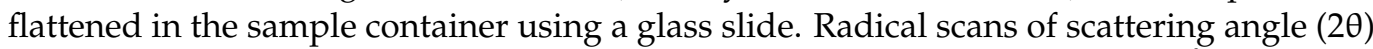
vs. intensity scans were recorded from 5 to $100^{\circ}$ with $\mathrm{CuK} \alpha$ radiation of $1.54 \AA$.

\subsubsection{Fourier Transform Infrared Spectroscopy (FTIR)}

The functional bonds present in the RSA and SiNPs were studied using an FTIR spectrophotometer (Perkin-Elmer1600). The absorbance of the dried sample was measured in the spectral range of $4000-500 \mathrm{~cm}^{-1}$ for 128 scans at a speed of $16 \mathrm{~cm} \mathrm{~s}^{-1}$. The spectral obtained was compared with the commercial nanosilica based on a literature review [4]. 


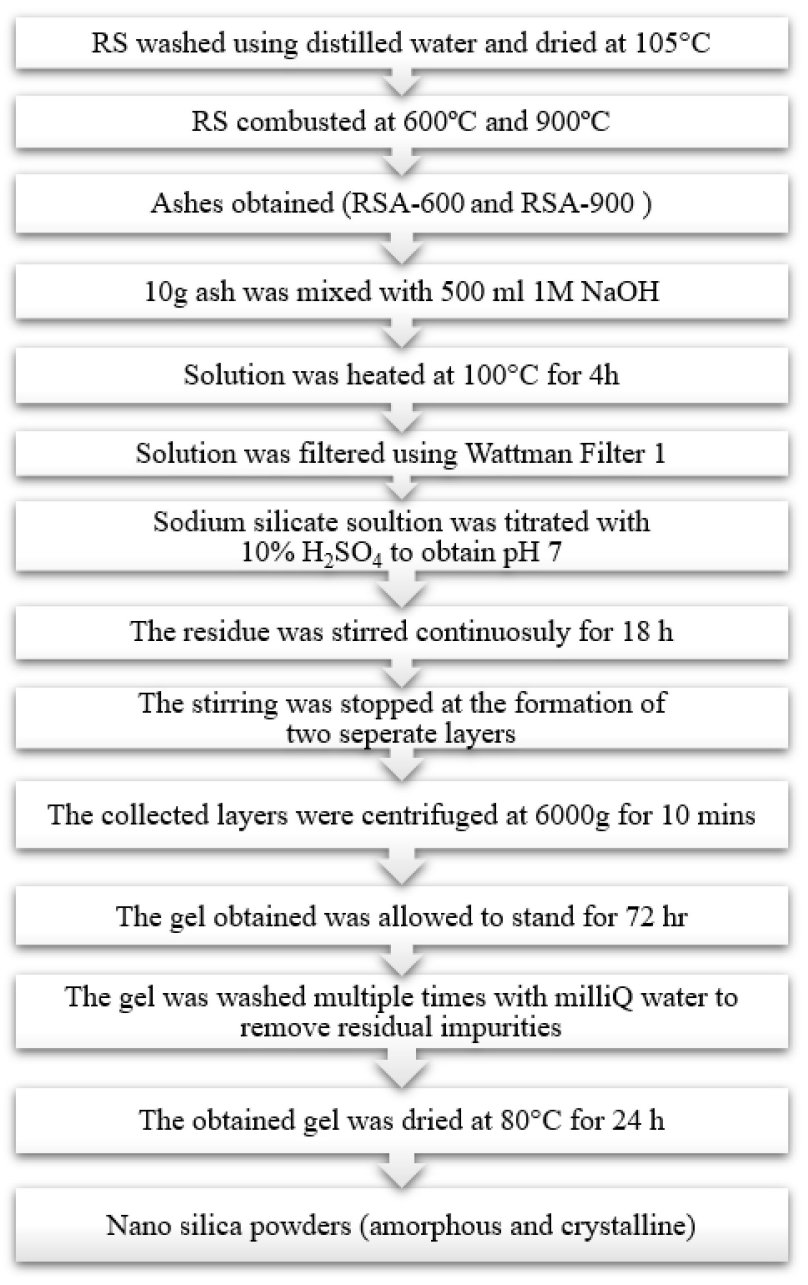

Figure 1. Synthesis of SiNPs using RSA combusted at $600{ }^{\circ} \mathrm{C}$ for amorphous particles and at $900{ }^{\circ} \mathrm{C}$ for crystalline particles.

\subsubsection{Field Emission Scanning Electron Microscope-Energy Dispersive Spectroscopy} (FE-SEM-EDX)

Microstructure and surface characteristics of the substrates (Raw RS, RSA, and SiNPs) were observed using FE-SEM-EDX (Field Emission Scanning Electron Microscope with Oxford-EDX system IE 250 X Max 80, The Netherlands). The dehydrated sample was mounted on the carbon tape. Gold sputtering was performed under vacuum $120 \mathrm{~s}$ with an acquisition time of $2 \mathrm{~min}$, beam accelerating voltage of $10 \mathrm{kV}$ at beam aperture $(30 \mathrm{~mm})$, with a working distance of $10 \mathrm{~mm}$ and probe current of $3 \times 10^{-10} \mathrm{~A}$. Mean EDX count rate was kept as $1600 \pm 200$ cps.

\subsubsection{Transmission Electron Microscopy (TEM)}

TEM analyses were performed by dissolving $5 \mathrm{mg}$ of samples (RSA and SiNPs) in $50 \mathrm{~mL}$ of double distilled water and kept for $30 \mathrm{~min}$ ultrasonication. Next, $10 \mu \mathrm{L}$ of the suspension $(0.005 \% w / w)$ was mounted on carbon-coated copper grids. The shape and size of the samples prepared were characterized by TEM (JEOL JEM-1400) at an accelerating voltage of $100 \mathrm{kV}$. The diameter and size distribution of synthesized SiNPs was calculated using ImageJ software.

\subsubsection{Surface Area and Porosity}

A Brunauer-Emmett-Teller (BET) of the make (Micromeritics ASAP 2010, USA) was used to analyze the surface area of synthesized SiNPs at $77 \mathrm{~K}$ in $\mathrm{N}_{2}$ atmosphere. The 
pore size distribution of the catalyst was calculated from the Barret-Joyner-Halenda (BJH) method using the adsorption data at relative pressure $\mathrm{P} / \mathrm{P}_{0}-0.990$.

\subsubsection{Photocatalytic Degradation of Methylene Blue Dye}

The photocatalytic effect of different concentrations of the optimum synthesized SiNPs $(0.2-0.5 \mathrm{~g} / \mathrm{L})$ on methylene blue (100 ppm) at alkaline $\mathrm{pH} 11.0$ was investigated following the protocols of Saleh and Dijaja [29] and Aly and Elhamid [26] with slight modifications. The photocatalytic experiment was conducted in a glass beaker equipped with continuous stirring under exposure to ultraviolet light (Philips $30 \mathrm{~W}$, two tubes). Different suspensions were swirled in the dark for $30 \mathrm{~min}$ before irradiation to obtain a colloidal solution. The beakers were placed at a $15 \mathrm{~cm}$ distance from the light source. The samples were extracted every $2 \mathrm{~h}$ and centrifuged at 10,000 rpm for $5 \mathrm{~min}$, and the study was conducted for $2 \mathrm{~h}$. The absorbance of the solution was determined using a BioTek Epoch 2 microplate spectrophotometer at $630 \mathrm{~nm}(\lambda \max )$, corresponding to the maximum absorption of methylene blue. The dye removal efficiency percentage was calculated as $\left(\mathrm{A}_{0}-\mathrm{A} t\right) / \mathrm{A}_{0} \times 100$, where $\mathrm{A}_{0}$ and $\mathrm{A}_{t}$ are the initial and final dye concentrations at time $t$, respectively.

\section{Results}

\subsection{X-ray Diffraction Analysis}

The XRD analysis of RSA-600 depicted a broad hump between $20.52^{\circ}-22.71^{\circ}$, indicating the material to be amorphous (Figure 2A), possessing the ability for adsorption; whereas RSA-900 indicated sharp peaks between $20^{\circ}$ and $30^{\circ}$ (Figure 2B), documented to decrease the available surface area, thus restricting the adsorption potential [8].
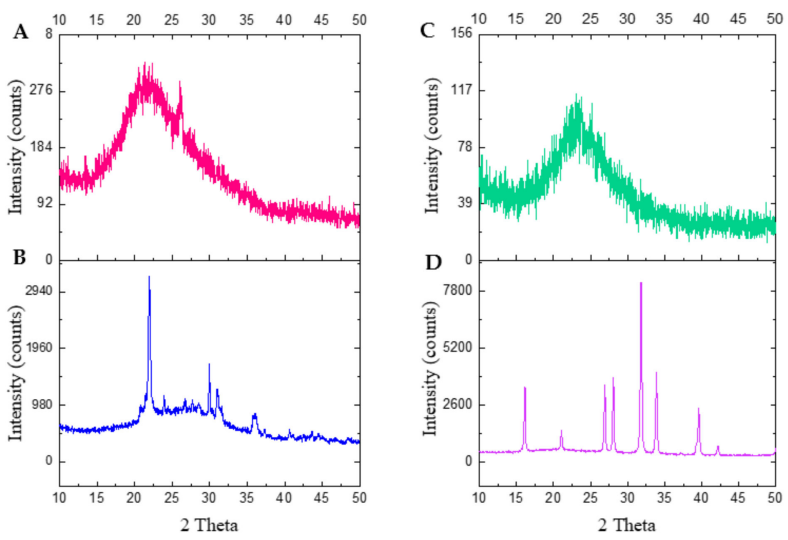

Figure 2. XRD pattern (A) RS ash obtained at $600{ }^{\circ} \mathrm{C}$ (RSA-600). (B) RS ash obtained at $900{ }^{\circ} \mathrm{C}$ (RSA-900). (C) SiNPs synthesized using RS ash obtained at $600^{\circ}$ C. (D) SiNPs synthesized using RS ash obtained at $900{ }^{\circ} \mathrm{C}$.

The synthesis process of SiNPs carried out using RSA-600 depicted a broad peak centered at $22^{\circ}$; the absence of any other peaks confirmed the SiNPs to be of amorphous nature (Figure 2C). SiNPs synthesized from RSA-900 depicted the presence of crystalline components between $20^{\circ}-30^{\circ}$ with a crystallinity index of $65 \%$, calculated according to the methodology of Mendes et al. [32]. However, various other peaks signified the impurity of the synthesized product, as shown in Figure 2D. The results are in coherence with the findings of several other researchers, where the diffraction peaks at $2 \theta$ angles between $20^{\circ}$ and $30^{\circ}$ is documented to be the characteristic peak of silica $[6,33]$.

\subsection{EDX Analysis}

The EDX profiling of RSA-600 showed Si and O's presence and various other minor elements such as $\mathrm{Mg}, \mathrm{K}, \mathrm{Na}, \mathrm{Al}, \mathrm{S}, \mathrm{Fe}$ and $\mathrm{Ca}$, shown in Figure $3 \mathrm{~A}$. The profiling study of white RSA-900 also showed various elements along with $\mathrm{Si}$ and $\mathrm{O}$, with a low K content, 
as shown in Figure 3B. The amorphous SiNPs confirmed the presence of Si and O and the absence of any other impurities, thus validating the purity of the product obtained as depicted (Figure 3C). The crystalline SiNPs denoted small peaks for Na and S, which could be due to traces of residual elements left in the process of washing (Figure 3D).

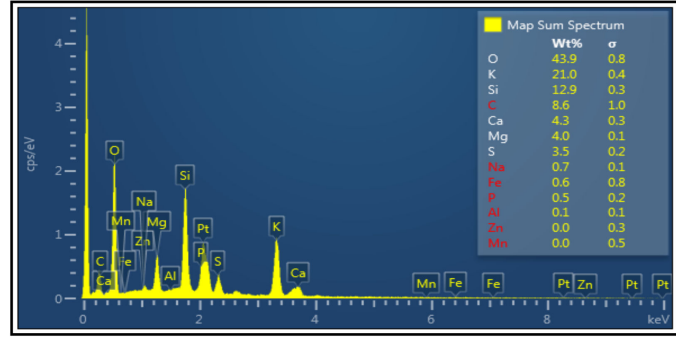

A

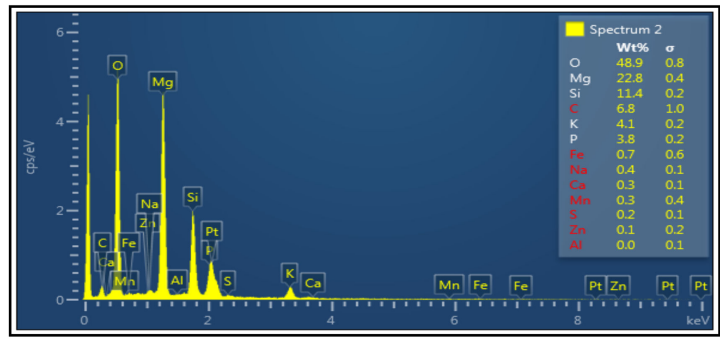

B

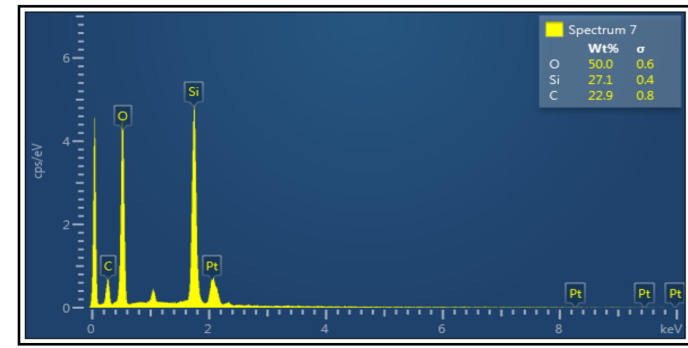

C

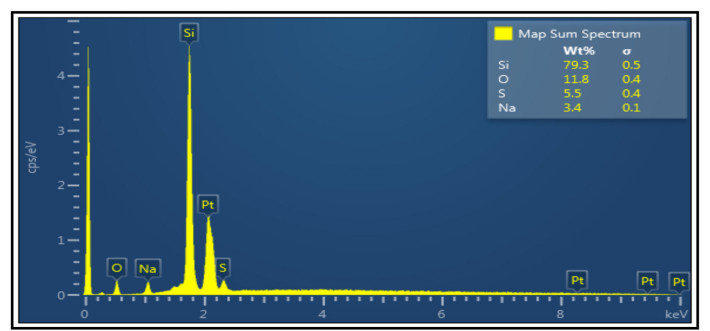

D

Figure 3. EDX analysis (A) RS ash obtained at $600{ }^{\circ} \mathrm{C}$ (RSA-600) (B) RS ash obtained at $900{ }^{\circ} \mathrm{C}$ (RSA-900) (C) SiNPs synthesized using RS ash obtained at $600^{\circ} \mathrm{C}$ (D) SiNPs synthesized using RS ash obtained at $900{ }^{\circ} \mathrm{C}$.

\subsection{Fourier Transform Infrared Analysis}

The Fourier transform IR analysis samples were recorded in the spectrum range of $4000-500 \mathrm{~cm}^{-1}$. FTIR of RSAs, presented in Figure 4, showed significant bands at $794 \mathrm{~cm}^{-1}, 1109 \mathrm{~cm}^{-1}$ corresponding to the symmetric and asymmetric stretching vibration of the $\mathrm{Si}-\mathrm{O}-\mathrm{Si}$ bond $[6,12]$. The peak observed for RSA-600 at $991 \mathrm{~cm}^{-1}$ signified the $\mathrm{Si}-\mathrm{OH}$ bond's bending vibration that diminished completely for RSA-900 [34]. The bonds $1629 \mathrm{~cm}^{-1}$ and $3448 \mathrm{~cm}^{-1}$ indicated the bending and stretching vibration of the $\mathrm{H}-\mathrm{OH}$ bond. The results are indicated in (Figure 4A,B). FTIR analyses of synthesized SiNPs showed broadband ranged between $3000-3500 \mathrm{~cm}^{-1}$ that indicated the presence of silanol group $(\mathrm{Si}-\mathrm{OH})$ bonding. The little band in the region of $1633 \mathrm{~cm}^{-1}$ corresponded to the bending vibrations of $\mathrm{H}-\mathrm{O}-\mathrm{H}$ (water molecules). The dominant peak at $1097 \mathrm{~cm}^{-1}$ was due to the asymmetric vibration of the $\mathrm{Si}-\mathrm{O}-\mathrm{Si}$ bond. The band at $789 \mathrm{~cm}^{-1}$ corresponded to $\mathrm{Si}-\mathrm{O}-\mathrm{Si}$ bond stretching [13,35], as shown in Figure 4C,D. A comparison of the spectral values obtained, and literature reports are briefly outlined in Table 1.

Table 1. Infrared bands observed in ashes (RSA-600, RSA-900), SiNPs (amorphous and crystalline).

\begin{tabular}{cccccc}
\hline RSA-600 & RSA-900 & $\begin{array}{c}\text { SiNPs } \\
\text { (Amorphous) }\end{array}$ & $\begin{array}{c}\text { SiNPs } \\
\text { (Crystalline) }\end{array}$ & Literature & $\begin{array}{c}\text { Functional } \\
\text { Groups }\end{array}$ \\
\hline 459 & 470 & 462 & 452 & $460[36]$ & $\mathrm{Si}-\mathrm{O}$ \\
1091 & 11,081 & 1073 & 1101 & $1033[12]$ & $\mathrm{Si}-\mathrm{O}-\mathrm{Si}$ \\
3474 & 3421 & 3423 & $\mathrm{NA}$ & $3000-3500[13]$ & $\mathrm{Si}-\mathrm{OH}$ \\
NA & $\mathrm{NA}$ & 1663 & 1641 & $1600[35]$ & $\mathrm{H}-\mathrm{OH}$ \\
795 & 775 & 796 & 817 & $796[6]$ & $\mathrm{Si}-\mathrm{O}-\mathrm{Si}$ \\
\hline
\end{tabular}

RSA 600-Rice straw ash obtained at $600^{\circ} \mathrm{C}$; RSA 900-Rice straw ash obtained at $900^{\circ} \mathrm{C}$; SiNPs-Silica nanoparticles. 

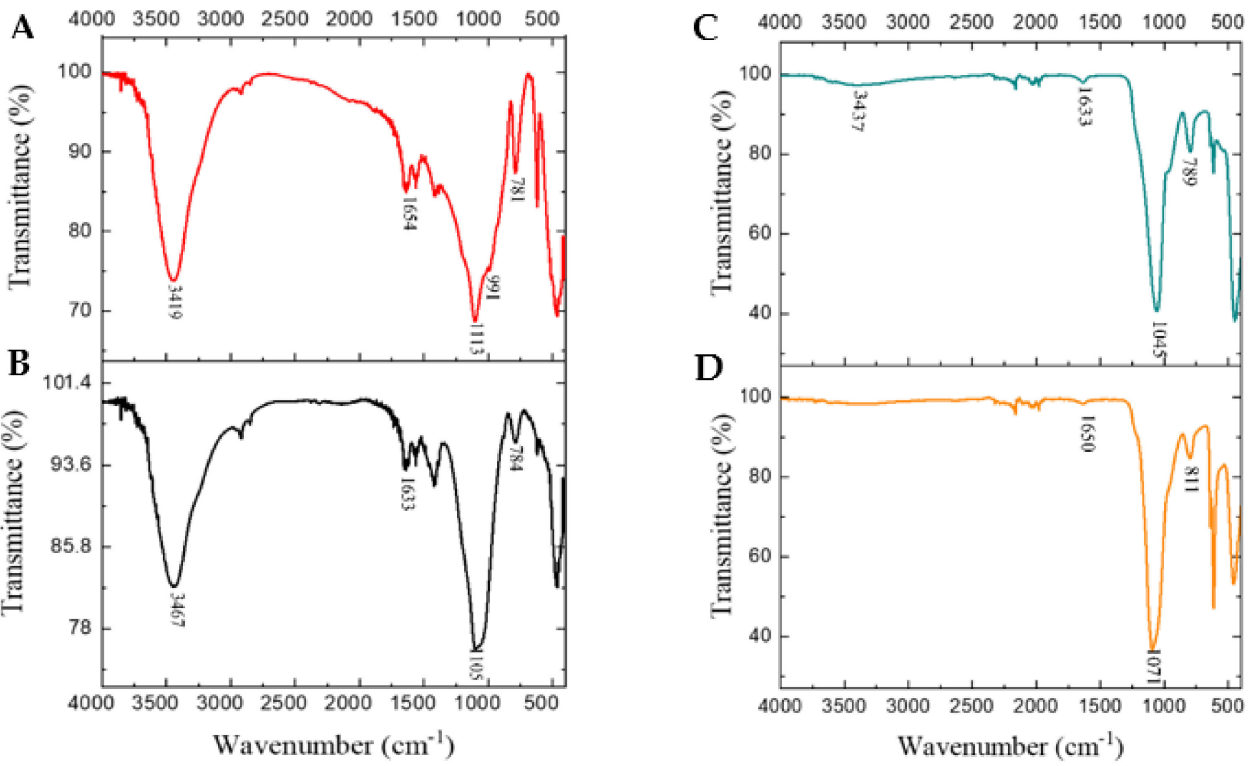

Figure 4. FTIR analysis (A) RS ash obtained at $600{ }^{\circ} \mathrm{C}$ (RSA-600). (B) RS ash obtained at $900{ }^{\circ} \mathrm{C}$ (RSA-900). (C) SiNPs synthesized using RS-600. (D) SiNPs synthesized using RS-900.

\subsection{Morphology Studies}

FE-SEM analysis of RS showed a stable, well-defined structure (Figure 5A). The microscopic analysis of RS ash (RSA-600 and RSA-900) showed a homogeneous distribution of dumbbell-shaped phytoliths commonly referred to as silica bodies over the entire surface (Figure 5B,C). The TEM analysis of RSAs showed the agglomeration of small circular bodies over the entire surface (Figure 5D,E).
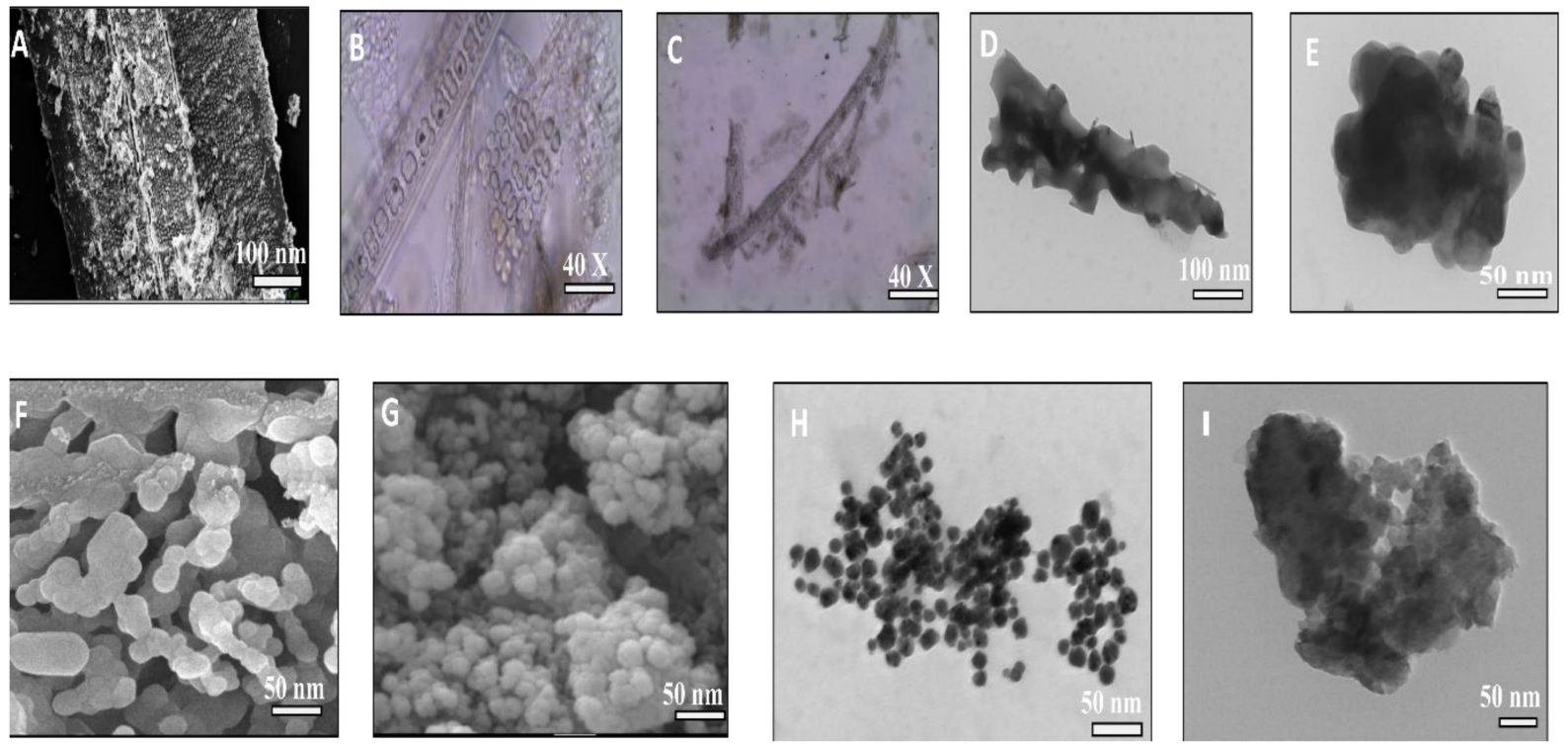

Figure 5. (A) FESEM micrographs of raw RS at 500 X. (B) Microscopic images of RSA-600 at 40X. (C) Microscopic images of RSA-900 D at 40 X. (D) TEM micrographs of RSA-600 at $120 \mathrm{kV}$. (E) TEM micrographs of RSA-900 at 120 kV. (F) FE-SEM micrographs of amorphous SiNPs at 10 kX. (G) FESEM micrographs of crystalline SiNPs at $10 \mathrm{kX}$. (H) TEM micrographs of amorphous SiNPs at $120 \mathrm{kV}$. (I) TEM micrographs of crystalline SiNPs at $120 \mathrm{kV}$.

FE-SEM analysis of amorphous SiNPs synthesized by RSA-600 depicted the particles of spheroid morphology with loose aggregates compared to crystalline SiNPs synthesized 
by RSA-900 (Figure 5F,G). The formation of aggregates could be attributed to the gel-like property of the hydrated silica and its high surface area [7,11,12]. TEM analysis revealed the amorphous SiNPs to be spherical, with the average particle size of $27.47 \mathrm{~nm}$ possessing little agglomeration. In contrast, crystalline SiNPs possessed average particle size of $52.79 \mathrm{~nm}$ with high agglomeration (Figure 5H,I). The results obtained can be well attested by the findings of Bahrami et al. [10] and Lu et al. [6] where it was postulated that high temperature leads to the formation of crystalline silica, keeping the Si bonds intact.

\subsection{Surface Area and Porosity Studies}

BET analysis revealed that amorphous SiNPs possessed a specific surface area (SSA) of $226.811 \mathrm{~m}^{2} / \mathrm{g}$ with an average pore volume of $1.144 \mathrm{~cm}^{3} / \mathrm{g}$, whereas the crystalline SiNPs had a BET SSA of $84.45 \mathrm{~m}^{2} / \mathrm{g}$ with a pore volume of $0.497 \mathrm{~cm}^{3} / \mathrm{g}$. Nitrogen adsorptiondesorption isotherm for the amorphous and crystalline SiNPs are shown in Figure 6A,B. The results were in line with the findings of Beidaghy Dizaji et al. [37] who documented that the porosity of silica-rich ashes diminish once the crystallinity fraction is higher than $10 \mathrm{wt} . \%$. Didamony et al. [38] reported a surface area of $160 \mathrm{~m}^{2} / \mathrm{g}$ from SiNPs extracted using sodium silicate solution, while Yuvakumar et al. [39] reported the amorphous synthesized SiNPs with a surface area of $274 \mathrm{~m}^{2} / \mathrm{g}$ and an average pore diameter of $1.46 \mathrm{~nm}$.

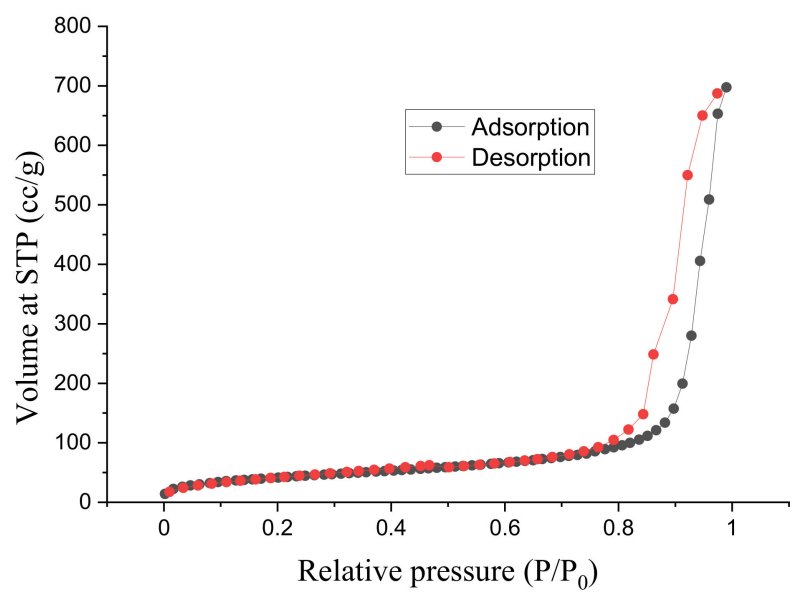

A

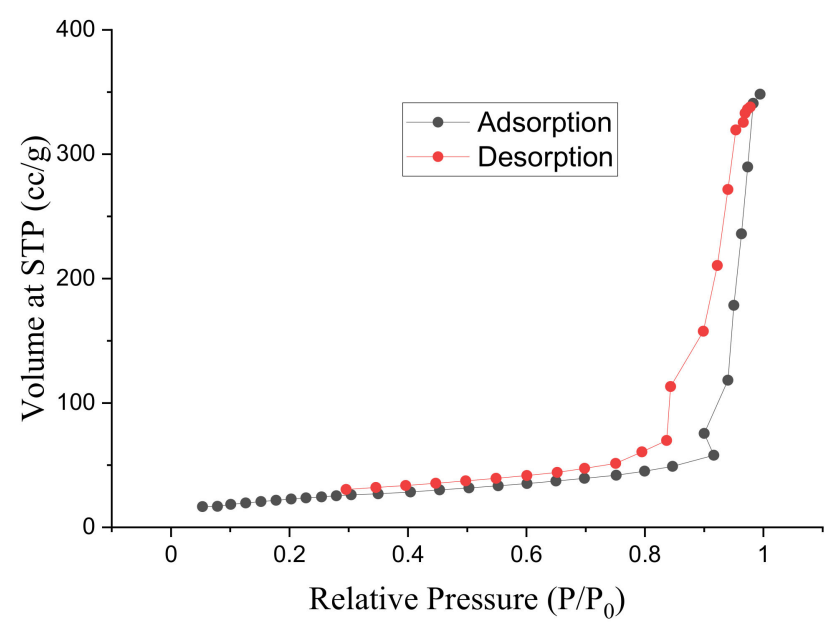

B

Figure 6. Nitrogen adsorption-desorption isotherms of (A) amorphous SiNPs (B) crystalline SiNPs. 
The results attested the findings that the amorphous SiNPs had significantly better attributes when compared to the crystalline SiNPs, thus increasing its utility in industrial sectors.

\subsection{Decolorization of Cationic Dye Methylene Blue Using Amorphous SiNPs}

The photocatalytic degradation studies tested the effect of different concentrations of SiNPs on a constant concentration of methylene blue dye (100 ppm). The studies reflected that the dye was efficiently degraded by $66.26 \%$ within the first $10 \mathrm{~min}$ by the SiNPs at 50 ppm concentration. Degradation of the dye at the lowest SiNPs concentration of 10 ppm did not reveal any observable degradation pattern. It showed a similar trend as to the degradation process without SiNPs (Figure 7A). This could be possibly explained owing to the availability of fewer adsorption sites of SiNPs at a relatively high concentration of dye. Decolorization of $\sim 100 \%$ was achieved within the initial 30 min of the study for the dye treated with SiNPs.

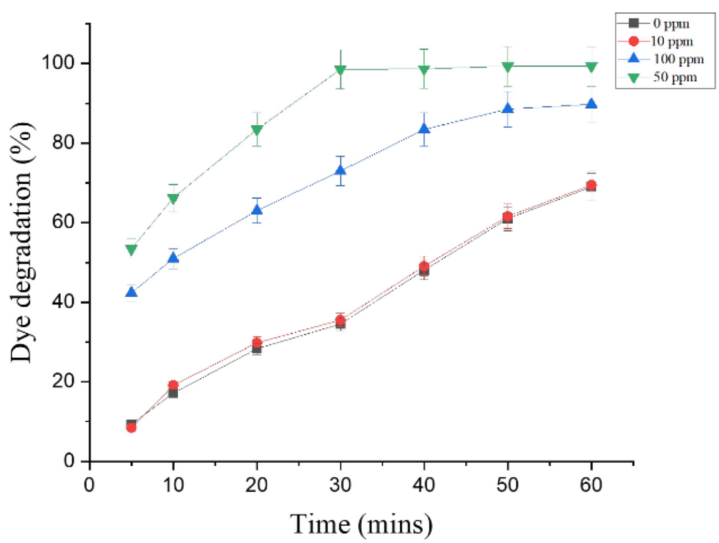

A

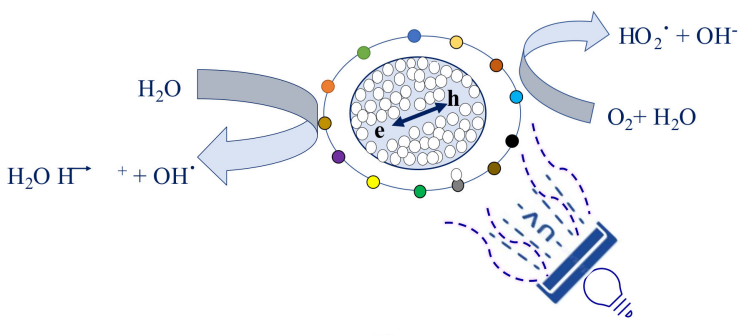

B

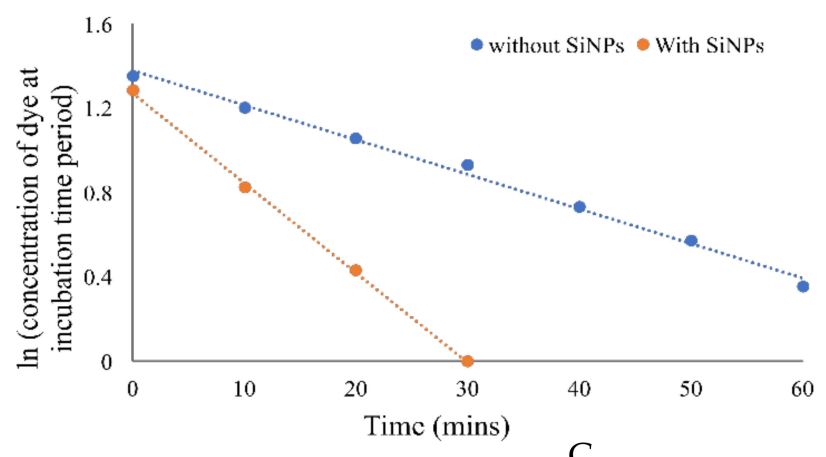

C

Figure 7. (A) Decolorization of methylene blue (MB) under the effect of UVC irradiation and different concentrations of SiNPs (B) Schematic representation of photocatalytic mechanism of methylene blue degradation by SiNPs (C) First-order kinetics plot of dye degradation, denoted by ( . . .) with SiNPs and by (-) without SiNPs.

The result obtained could be well correlated to the effect of UV-C irradiation that assisted in the induction of the direct photolysis on the dye. Moreover, as the UV-C photons have a shorter penetration potential through photocatalyst particles, the possibility of electron-hole recombination is minimized due to shorter travel distances, leading to higher photocatalytic activity $[27,29,40]$. The high surface area of amorphous SiNPs accelerated the degradation process. A comprehensive detail of dye decolorization documented by numerous researchers using SiNPs is highlighted in Table 2. 
Table 2. Nanosilica in photocatalytic degradation of textile dye effluents.

\begin{tabular}{|c|c|c|c|c|c|c|c|}
\hline Dye & $\begin{array}{c}\text { Concentration (Dye) } \\
\text { and } \mathrm{pH}\end{array}$ & Source of SiNPs & $\begin{array}{l}\text { Concentration } \\
\text { (Nanosilica) }\end{array}$ & Source & Degradation (\%) & Time & References \\
\hline Crystal Violet & $50 \mathrm{mg} / \mathrm{L} ; \mathrm{pH} 7$ & Rice husk & $1 \mathrm{~g} / \mathrm{L}$ & Ultrasound & $80 \%$ & $60 \mathrm{~min}$ & Peres et al. [41] \\
\hline Methyl red & $0.05 \mathrm{Mm} / 100 \mathrm{~mL} ; \mathrm{pH} 7$ & Rice husk & $1 \mathrm{~g} / 100 \mathrm{~mL}$ & Sunlight & $95 \%$ & $120 \mathrm{~min}$ & Vinoda et al. [42] \\
\hline Methylene blue & $\begin{array}{l}50 \mathrm{ppm} / 50 \mathrm{~mL} ; \\
\text { pH-not reported }\end{array}$ & Rice husk & $50 \mathrm{mg} / 100 \mathrm{~mL}$ & $\begin{array}{c}\text { Ceramic material } \\
\text { based on amorphous } \\
\text { SiNPs }\end{array}$ & $80 \%$ & $30 \mathrm{~min}$ & Tolba et al. [25] \\
\hline Methylene blue & 100 mg/L; pH 11 & Yellow sand & $10 \mathrm{~g} / \mathrm{L}$ & Ultraviolet light & $100 \%$ & $90 \mathrm{~s}$ & Aly and Elhamid [26] \\
\hline Methylene blue & 50 ppm; pH 7 & $\mathrm{ZnO} / \mathrm{SiO}_{2}$ xerogel & $0.075 \mathrm{~g} / \mathrm{L}$ & Visible light & $100 \%$ & $30 \mathrm{~min}$ & Stanley [27] \\
\hline Acridine orange & $1 \times 10^{-5} \mathrm{M}$ & $\begin{array}{c}\text { 3-aminopropyl- } \\
\text { functionalized silica } \\
\text { NPs }\end{array}$ & $10 \mathrm{mg} / 3 \mathrm{~mL}$ & Ultraviolet light & $58 \%$ & $50 \mathrm{~min}$ & Selvaggi et al. [43] \\
\hline Acid ornage & $150 \mathrm{mg} / \mathrm{L}$ & Sugar cane ash & $1 \mathrm{~g} / \mathrm{L}$ & Not reported & $80 \%$ & $30 \mathrm{~min}$ & Rovani et al. [44] \\
\hline Malachite green & $20 \mathrm{mg} / \mathrm{L} ; \mathrm{pH} 9$ & $\begin{array}{c}\mathrm{Fe}_{3} \mathrm{O}_{4} @ \mathrm{SiO}_{2}-\mathrm{COOH} \\
\text { NPs }\end{array}$ & $0.5 \mathrm{~g} / \mathrm{L}$ & Not reported & $97.5 \%$ & $120 \mathrm{~min}$ & Galangash et al. [45] \\
\hline
\end{tabular}


3.6.1. Mechanism of Photocatalytic Degradation of Methylene Blue Using SiNPs

The mechanism of photocatalytic activity can be explained owing to the ability of SiNPs to be photoexcited under UV irradiation. This phenomenon can be supported by the charge transfer from $\mathrm{Si}-\mathrm{O}$ bonding orbital to $2 \mathrm{p}$ non-bonding orbital of non-bridging oxygen. Interestingly, as observed in FTIR studies, the presence of $\mathrm{Si}-\mathrm{O}$ and $\mathrm{Si}-\mathrm{OH}$ groups imparts a negative charge on the silica surface, thus offering the SiNPs to serve as an excellent medium for adsorbent cationic dyes $[43,46]$.

On striking the surface of $\mathrm{SiO}_{2}$ by UV light, an electron transfer occurs from the valence band to the conduction band, generating a positive hole in the valence band $\left(\mathrm{v}_{\mathrm{b}}\right)$ and a negative hole in the conduction band $\left(c_{b}\right)$, leading to the formation of active photocatalytic centers on the surface of SiNPs (Equation (1)). The $\mathrm{v}_{\mathrm{b}}$ hole further interacts with chemisorbed $\mathrm{H}_{2} \mathrm{O}$ molecules to form $\mathrm{OH}$ radicals that successively attacks dye molecules (Equation (2)). The generation of heat in this process could be ascribed due to the combination of $\mathrm{e}_{\mathrm{cb}}{ }^{-}$and $\mathrm{h}_{\mathrm{vb}}{ }^{+}$on the particle's surface. A plausible cause for dye decolorization can be attributed to the hydroxyl attack and conduction of the experiment at high $\mathrm{pH}$, increasing $\mathrm{OH}^{-}$groups on the silica surface, leading to an acceleration of dye degradation process $[25,47]$.

A diagrammatic sketch of the mechanism is shown in Figure 7B.

$$
\begin{gathered}
\mathrm{SiO}_{2}+\mathrm{h} v \rightarrow \mathrm{e}_{\mathrm{cb}}{ }^{-}+\mathrm{h}_{\mathrm{vb}}{ }^{+} \\
\mathrm{HO}_{2}+\mathrm{OH}^{-}+\mathrm{h}_{\mathrm{vb}}{ }^{-} \rightarrow \mathrm{OH}
\end{gathered}
$$

The $\mathrm{e}_{\mathrm{cb}}{ }^{-}$and $\mathrm{h}_{\mathrm{vb}}{ }^{+}$recombine on the particle's surface within nanoseconds, and the generated energy becomes dissipated in the form of heat. $\mathrm{e}_{\mathrm{cb}}-$ further reacts with the acceptor dissolved $\mathrm{O}_{2}$ and is transformed to a super oxide radical anion $\left(\mathrm{O}_{2}{ }^{-}\right)$, leading to the further growth of $\mathrm{O}_{2} \mathrm{H}$ molecules (3):

$$
\mathrm{O}_{2}+\mathrm{e}_{\mathrm{cb}}^{-} \rightarrow \mathrm{O}_{2}^{-\cdot}+\left(\mathrm{H}^{+}+{ }^{-} \mathrm{OH}\right) \rightarrow \mathrm{HO}_{2}+\mathrm{OH}^{-}
$$

$\mathrm{h}_{\mathrm{vb}}{ }^{+}$interacts with the donor ${ }^{-} \mathrm{OH}$ and $\mathrm{O}_{2} \mathrm{H}$ forming ${ }^{\circ} \mathrm{OH}$ radical that attacks the $\mathrm{MB}$ in the following manner:

$$
\mathrm{HO}_{2}+\mathrm{OH}^{-}+\mathrm{h}_{\mathrm{vb}}{ }^{-} \rightarrow \mathrm{OH}
$$

The governing factor monitoring the efficiency of SiNPs is the amount of $\mathrm{OH}$ radicals generated. Since the hydroxyl groups on the SiNPs surface are attached to the silicon atom, they are termed as silanols. The $\mathrm{OH}$ groups present in the silanols can preferentially complex particular chemicals or metal ions, imparting functionality to SiNPs [48]. It is worth highlighting that shifting the $\mathrm{pH}$ towards the alkaline range led to a dramatic boost in dye degradation. Henceforth, varying the $\mathrm{pH}$ value can significantly impact the interactions of various compounds with silanols. Subsequently, any factor that contributes to the generation of $\mathrm{OH}$ radicals lead to an enhancement in the photocatalytic degradation process of methylene blue.

\subsubsection{Kinetic Study of Dye Degradation}

Kinetic studies were performed for the optimal concentration of SiNPs (50 ppm) that aided in the complete degradation of the methylene blue dye compared to the dye treated under UVC. The effect of SiNPs on dye decolorization indicated first-order kinetics. The linear form of the first-order rate equation is denoted by Equation (5), and the half-life $\left(t_{0.5}\right)$ of dye decolorization was calculated using Equation (6) [47]:

$$
\begin{aligned}
\ln \mathrm{D}_{\mathrm{Ab}} & =-\mathrm{kt}+\ln \mathrm{D}_{\mathrm{A} 0} \\
\mathrm{t}_{0.5} & =0.693 / \mathrm{k}
\end{aligned}
$$


where $\mathrm{D}_{\mathrm{Ab}}$ is the dye absorbance at different incubation times, $\mathrm{k}$ is decolorization rate constant, $\mathrm{D}_{\mathrm{A} 0}$ is the initial absorbance of the dye, and $\mathrm{t}_{0.5}$ is the time required to decolorize $50 \%$ dye.

The logarithm plot of dye concentration vs. treatment time with SiNPs exhibited a rate constant $(\mathrm{k})$ of $0.102 \mathrm{~min}^{-1}$ and $\mathrm{t}_{0.5}$ of $6.79 \mathrm{~min}$. In contrast, the untreated dye exhibited a rate constant of $0.044 \mathrm{~min}^{-1}$ and $\mathrm{t}_{0.5}$ of $15.75 \mathrm{~min}$, reported for the $30 \mathrm{~min}$ study. The results obtained thus positively attest to the enhanced effect in dye degradation due to incorporation of the SiNPs as shown in Figure 7C.

\subsubsection{FTIR Studies of Methylene Blue Decolorization}

The methylene blue molecular structure transformation was further evaluated by the FTIR analysis of the treated and untreated samples. UV-Vis spectra illustrated the presence of aromatics along with conjugates of $\mathrm{N}-\mathrm{S}$ heterocycle group and phenothiazine structure [29]. The results in Figure 8 showed that the broad peak at $3451 \mathrm{~cm}^{-1}$ was determined as the $\mathrm{O}-\mathrm{H}$ stretching vibration of water molecules. It could be seen that the peak corresponding to $\mathrm{C}-\mathrm{H}$ absorption of benzene ring occurred at $2975 \mathrm{~cm}^{-1}$. The peak at $2105 \mathrm{~cm}^{-1}$ denoted the stretching vibration peak of the methyl group. The $\mathrm{C}=\mathrm{C}$ framework corresponding to benzene ring vibration and the $C=N$ stretching vibration was found at $1646 \mathrm{~cm}^{-1}$. The absorption peak at $1420 \mathrm{~cm}^{-1}$ was related to another typical vibration in methyl bending. Other prominent peaks were in the vibration of $\mathrm{C}=\mathrm{O}$ and $-\mathrm{C}-\mathrm{C}$ at $1206 \mathrm{~cm}^{-1}$ and $991 \mathrm{~cm}^{-1}$. It was noticed that the intensity of absorption peaks for $\mathrm{C}=\mathrm{N}$ and $\mathrm{O}-\mathrm{H}$ had significant decrease in $\mathrm{C}=\mathrm{C}$ aromatic stretch in the treated sample, indicating a change in chemical composition. This could be possibly attributed to the breakdown of the $\mathrm{N}-\mathrm{S}$ heterocyclic compound during the degradation process $[25,26,49]$. The characteristic peak of benzene and $\mathrm{C}-\mathrm{H}$ bending vibration of aromatic $\mathrm{C}-\mathrm{H}$ declined substantially, indicating the variation in chemical compositions of phenyl groups.

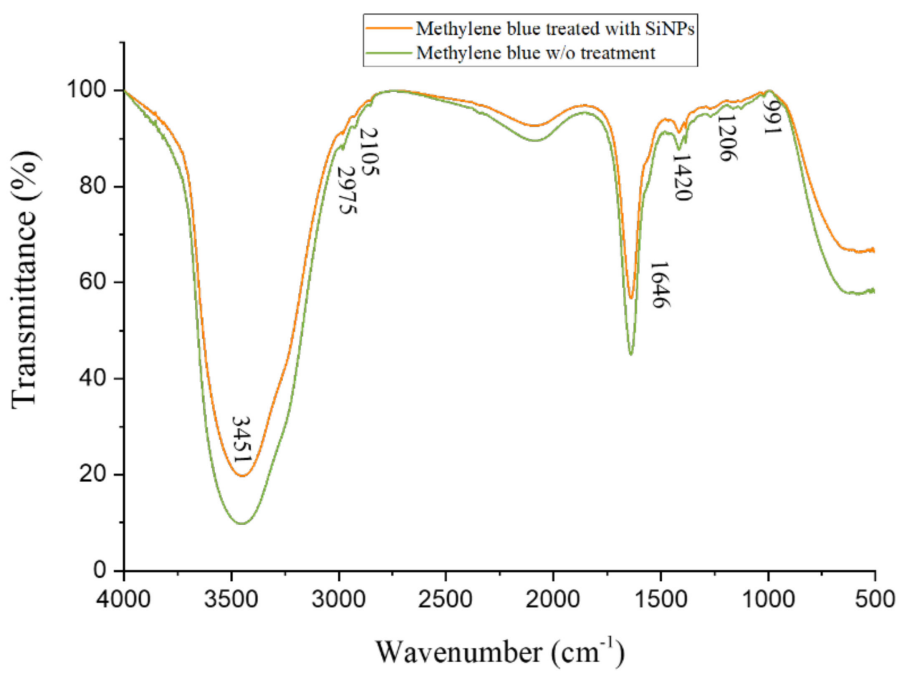

Figure 8. FTIR spectrum of methylene blue about its treatment with SiNPs.

It henceforth can be deduced from the spectra that the adsorption of methylene blue on the surface of SiNPs led to a remarkable change in infrared bands intensities, retaining its positions.

Stanley [26], Salimi [40] and Singh [43] hypothesized that the conjugate structure of $\mathrm{N}-\mathrm{S}$ heterocyclic underwent variations in chemical composition, and consequently the aromatic ring was oxidized to open the ring leading to degradation of the dye molecules during the photocatalysis reaction. The result obtained provides new insight into potential waste usage and utilizing the low-cost synthesized SiNPs for dye degradation. 


\section{Conclusions}

The study revealed that RS combusted at $600^{\circ} \mathrm{C}$ served as an ideal condition for synthesizing amorphous SiNPs. The findings and characterization postulated that the amorphous SiNPs served better attributes when compared to crystalline SiNPs, establishing that all the researchers/stakeholders working in this domain can note that lower temperature offers a more sustainable route in product synthesis. This first-hand analysis provided the particulars pertaining to temperature's crucial role and effect on the characterization and properties of SiNPS. The efficacy of the green synthetic route for amorphous SiNPs holding potential applications in different sectors was accessed in the field of wastewater and textile effluents for degradation of the toxic dye methylene blue. Additionally, incorporating microwave, sonication, conjugation of substrates as laccase, surface modification of SiNPs can further be attempted towards the dye degradation process. However, the study has much to offer in terms of optimizing the synthesis process via integrating surfactants, catalyst, residence time, etc., to enhance the surface area and pore size of SiNPs; that will further assist in the degradation process with a minimal dose of SiNPs and enhancing its utility as an adsorbent in different industrial sectors. Contemplating the abundance of agro-waste RS worldwide, the study establishes a background in converting the waste to a value-added product, providing a comprehensive and viable sustainable resolution towards stubble burning to achieve the SDGs 3, 7, 8 and 13 .

Author Contributions: Conceptualization, S.S. and H.B.D.; methodology, G.S. and H.B.D.; software, G.S.; validation, H.B.D. and S.S.; formal analysis, G.S. and H.B.D.; investigation, G.S. and H.B.D.; resources, H.B.D. and S.S.; data curation, G.S.; writing-original draft preparation, G.S.; writingreview and editing, H.B.D. and S.S.; visualization, H.P. and S.S.; supervision H.P. and S.S.; project administration, H.B.D. and S.S.; funding acquisition, H.B.D. and S.S. All authors have read and agreed to the published version of the manuscript.

Funding: The APC was funded by the Thermochemical Conversion department of DBFZ Deutsches Biomasseforschungszentrum gemeinnützige $\mathrm{GmbH}$.

Institutional Review Board Statement: Not applicable.

Informed Consent Statement: Not applicable.

Data Availability Statement: The data that support the findings of this study are available upon request from the authors.

Acknowledgments: The authors are thankful to the Indian Institute of Technology, New Delhi, and DBFZ Deutsches Biomasse for schungszentrumgemeinnützige GmbH, Leipzig, Germany, for providing the research funds and financial support.

Conflicts of Interest: The authors declare no conflict of interest.

\section{References}

1. Beidaghy Dizaji, H.; Zeng, T.; Hartmann, I.; Enke, D.; Schliermann, T.; Lenz, V.; Bidabadi, M. Generation of high-quality biogenic silica by combustion of rice husk and rice straw combined with pre- and post-treatment strategies-A review. Appl. Sci. 2019, 9, 1083. [CrossRef]

2. Kumar, S.; D'Silva, T.C.; Chandra, R.; Malik, A.; Vijay, V.K.; Misra, A. Strategies for boosting biomethane production from rice straw: A systematic review. Bioresour. Technol. Rep. 2021, 15, 100813. [CrossRef]

3. Tipayarom, A.; Oanh, N.T.K. Influence of rice straw open burning on levels and profiles of semi-volatile organic compounds in ambient air. Chemosphere 2020, 243, 125379. [CrossRef]

4. Singh, G.; Arya, S.K. A review on management of rice straw by use of cleaner technologies: Abundant opportunities and expectations for Indian farming. J. Clean. Prod. 2020, 291, 125278. [CrossRef]

5. Marxen, A.; Klotzbücher, T.; Jahn, R.; Kaiser, K.; Nguyen, V.S.; Schmidt, A.; Schädler, M.; Vetterlein, D. Interaction between silicon cycling and straw decomposition in a silicon deficient rice production system. Plant Soil 2016, 398, 153-163. [CrossRef]

6. Lu, P.; Hsieh, Y.L. Highly pure amorphous silica nano-disks from rice straw. Powder Technol. 2012, 225, 149-155. [CrossRef]

7. Singh, G.; Tiwari, A.; Gupta, A.; Kumar, A.; Hariprasad, P.; Sharma, S. Bioformulation development via valorizing silica-rich spent mushroom substrate with Trichoderma asperellum for plant nutrient and disease management. J. Environ. Manag. 2021, 297, 113278. [CrossRef] 
8. Bahrami, A.; Pech-Canul, M.I.; Gutierrez, C.A.; Soltani, N. Effect of rice-husk ash on properties of laminated and functionally graded $\mathrm{Al} / \mathrm{SiC}$ composites by one-step pressureless infiltration. J. Alloys Compd. 2015, 644, 256-266. [CrossRef]

9. Beidaghy Dizaji, H.; Zeng, T.; Hölzig, H.; Bauer, J.; Klöß, G.; Enke, D. Ash transformation mechanism during combustion of rice husk and rice straw. Fuel 2022, 307, 121768. [CrossRef]

10. Bahrami, A.; Simon, U.; Soltani, N.; Zavareh, S.; Schmidt, J.; Pech-Canul, M.I.; Gurlo, A. Eco-Fabrication of hierarchical porous silica monoliths by ice-templating of rice husk ash. Green Chem. 2017, 19, 188-195. [CrossRef]

11. Bhattacharya, M.; Mandal, M.K. Synthesis of rice straw extracted nano-silica-composite membrane for $\mathrm{CO}_{2}$ separation. J. Clean Prod. 2018, 186, 241-252. [CrossRef]

12. Mor, S.; Manchanda, C.K.; Kansal, S.K.; Ravindra, K. Nanosilica extraction from processed agricultural residue using green technology. J. Clean. Prod. 2017, 143, 1284-1290. [CrossRef]

13. Kauldhar, B.S.; Yadav, S.K. Turning waste to wealth: A direct process for recovery of nano-silica and lignin from paddy straw agro-waste. J. Clean. Prod. 2018, 194, 158-166. [CrossRef]

14. Sachan, D.; Ramesh, A.; Das, G. Green synthesis of silica nanoparticles from leaf biomass and its application to remove heavy metals from synthetic wastewater: A comparative analysis. Environ. Nanotechnol. Monit. Manag. 2021, 16, 100467. [CrossRef]

15. Hassan, A.F.; Abdelghny, A.M.; Elhadidy, H.; Youssef, A.M. Synthesis and characterization of high surface area nanosilica from rice husk ash by surfactant-free Sol-Gel method. J. Sol-Gel Sci. Technol. 2014, 69, 465-472. [CrossRef]

16. Handojo, L.; Pramudita, D.; Mangindaan, D.; Indarto, A. Application of nanoparticles in environmental cleanup: Production, potential risks and solutions. Emerg. Eco-Friendly Green Technol. Wastewater Treat. 2020, 18, 45-76.

17. Liu, X.; Wang, Y.; Zhang, T.C.; Xiang, G.; Wang, X.; Yuan, S. One-Pot Synthesis of a Magnetic $\mathrm{TiO}_{2} / \mathrm{PTh} / \gamma-\mathrm{Fe}_{2} \mathrm{O}_{3} \mathrm{Heterojunction}$ Nanocomposite for Removing Trace Arsenite via Simultaneous Photocatalytic Oxidation and Adsorption. Ind. Eng. Chem. Res. 2020, 60, 528-540. [CrossRef]

18. Krawczyk, A.; Domagała-Świątkiewicz, I.; Lis-Krzyścin, A.; Daraż, M. Waste Silica as a Valuable Component of Extensive Green-Roof Substrates. Polish J. Environ. Stud. 2017, 26, 643-653. [CrossRef]

19. Liu, S.; Wang, Y.; Liao, C.; Wang, Y.; He, J.; Fu, C.; Yang, K.; Bai, Z.; Zhang, F. Nano silica diaphragm in-fiber cavity for gas pressure measurement. Sci. Rep. 2017, 7, 787. [CrossRef]

20. Le, T.M.; Tran, U.P.N.; Duong, Y.H.P.; Nguyen, Q.D.; Tran, V.T.; Mai, P.T.; Le, P.K. Sustainable bioethanol and value-added chemicals production from paddy residues at pilot scale. Clean Technol. Environ. Policy 2021, 1-13. [CrossRef]

21. Singh, P.; Srivastava, S.; Singh, S.K. Nanosilica: Recent progress in synthesis, functionalization, biocompatibility, and biomedical applications. ACS Biomater. Sci. Eng. 2019, 5, 4882-4898. [CrossRef]

22. Olivier, G.; Combrinck, R.; Kayondo, M.; Boshoff, W.P. Combined effect of nano-silica, super absorbent polymers, and synthetic fibres on plastic shrinkage cracking in concrete. Constr. Build. Mater. 2018, 192, 85-98. [CrossRef]

23. Zhang, H.; Goeppert, A.; Olah, G.A.; Prakash, G.K.S. Remarkable effect of moisture on the $\mathrm{CO}_{2}$ adsorption of nano-silica supported linear and branched polyethylenimine. J. $\mathrm{CO}_{2}$ Util. 2017, 19, 91-99. [CrossRef]

24. Salimian, S.; Zadhoush, A.; Naeimirad, M.; Kotek, R.; Ramakrishna, S. A review on aerogel: 3D nanoporous structured fillers in polymer-based nanocomposites. Polym. Compos. 2018, 39, 3383-3408. [CrossRef]

25. Tolba, G.M.K.; Barakat, N.A.M.; Bastaweesy, A.M.; Ashour, E.A.; Abdelmoez, W.; El-Newehy, M.H.; Al-Deyab, S.S.; Kim, H.Y. Effective and highly recyclable nanosilica produced from the rice husk for effective removal of organic dyes. J. Ind. Eng. Chem. 2015, 29, 134-145. [CrossRef]

26. Aly, H.F.; Abd-Elhamid, A.I. Photocatalytic degradation of methylene blue dye using silica oxide nanoparticles as a catalyst. Water Environ. Res. 2018, 90, 807-817. [CrossRef]

27. Stanley, R. Enhanced sunlight photocatalytic degradation of methylene blue by rod-like $\mathrm{ZnO}-\mathrm{SiO}_{2}$ nanocomposite. Optik 2019, 180, 134-143. [CrossRef]

28. Kusdianto, K.; Widiyastuti, W.; Shimada, M.; Qomariyah, L.; Winardi, S. Fabrication of $\mathrm{ZnO}^{-S_{i O}}$ nanocomposite materials prepared by a spray pyrolysis for the photocatalytic activity under UV and sunlight irradiations. In Proceedings of the IOP Conference Series: Materials Science and Engineering, Borovets, Bulgaria, 26-29 November 2020; IOP Publishing: Bristol, UK, 2020; Volume 778, p. 12105. [CrossRef]

29. Saleh, R.; Djaja, N.F. UV light photocatalytic degradation of organic dyes with Fe-doped ZnO nanoparticles. Superlattices Microstruct. 2014, 74, 217-233. [CrossRef]

30. Venkatramanan, V.; Shah, S.; Rai, A.K.; Prasad, R. Nexus between Crop Residue Burning, Bioeconomy and Sustainable Development Goals over North-Western India. Front. Energy Res. 2021, 8, 614212. [CrossRef]

31. Kalapathy, U.; Proctor, A.; Shultz, J. A simple method for production of pure silica from rice hull ash. Bioresour. Technol. 2000, 73, 257-262. [CrossRef]

32. Mendes, C.; Adnet, F.; Leite, M.; Furtado, C.R.G.; Sousa, A. Chemical, physical, mechanical, thermal and morphological characterization of corn husk residue. Cellul. Chem. Technol. 2015, 49, 727-735.

33. Sarkar, P.; Moyez, S.A.; Dey, A.; Roy, S.; Das, S.K. Experimental investigation of photocatalytic and photovoltaic activity of titania/rice husk crystalline nano-silica hybrid composite. Sol. Energy Mater. Sol. Cells 2017, 172, 93-98. [CrossRef]

34. Yan, F.; Jiang, J.; Chen, X.; Tian, S.; Li, K. Synthesis and characterization of silica nanoparticles preparing by low-temperature vapor-phase hydrolysis of $\mathrm{SiCl}_{4}$. Ind. Eng. Chem. Res. 2014, 53, 11884-11890. [CrossRef] 
35. Zamani, A.; Marjani, A.P.; Mousavi, Z. Agricultural waste biomass-assisted nanostructures: Synthesis and application. Green Process. Synth. 2019, 8, 421-429. [CrossRef]

36. Ferreira, C.S.; Santos, P.L.; Bonacin, J.A.; Passos, R.R.; Pocrifka, L.A. Rice Husk Reuse in the Preparation of $\mathrm{SnO}_{2} / \mathrm{SiO}_{2} \mathrm{Nanocom}^{-}$ posite. Mater. Res. 2015, 18, 639-643. [CrossRef]

37. Beidaghy Dizaji, H.; Zeng, T.; Enke, D. New fuel indexes to predict ash behavior for biogenic silica production. Fuel 2022, 310B, 122345. [CrossRef]

38. El-Didamony, H.; El-Fadaly, E.; Amer, A.A.; Abazeed, I.H. Synthesis and characterization of low cost nanosilica from sodium silicate solution and their applications in ceramic engobes. Bol. Soc. Esp. Cerám. Vidr. 2020, 59, 31-43. [CrossRef]

39. Yuvakkumar, R.; Elango, V.; Rajendran, V.; Kannan, N. High-Purity nano silica powder from rice husk using a simple chemical method. J. Exp. Nanosci. 2014, 9, 272-281. [CrossRef]

40. Kong, X.; Liu, X.; Li, J.; Yang, Y. Advances in pharmacological research of eugenol. Curr. Opin. Complement. Altern. Med. 2014, 1 , 8-11.

41. Peres, E.C.; Favarin, N.; Slaviero, J.; Almeida, A.R.F.; Enders, M.P.; Muller, E.I.; Dotto, G.L. Bio-nanosilica obtained from rice husk using ultrasound and its potential for dye removal. Mater. Lett. 2018, 231, 72-75. [CrossRef]

42. Vinoda, B.M.; Vinuth, M.; Bodke, Y.; Manjanna, J. Photocatalytic degradation of toxic methyl red dye using silica nanoparticles synthesized from rice husk ash. J. Env. Anal. Toxicol. 2015, 5, 525-2161. [CrossRef]

43. Selvaggi, R.; Tarpani, L.; Santuari, A.; Giovagnoli, S.; Latterini, L. Silica nanoparticles assisted photodegradation of acridine orange in aqueous suspensions. Appl. Catal. B Environ. 2015, 168, 363-369. [CrossRef]

44. Rovani, S.; Santos, J.J.; Corio, P.; Fungaro, D.A. Highly pure silica nanoparticles with high adsorption capacity obtained from sugarcane waste ash. ACS Omega 2018, 3, 2618-2627. [CrossRef]

45. Mohammadi Galangash, M.; Mohaghegh Montazeri, M.; Ghavidast, A.; Shirzad-Siboni, M. Synthesis of carboxyl-functionalized magnetic nanoparticles for adsorption of malachite green from water: Kinetics and thermodynamics studies. J. Chin. Chem. Soc. 2018, 65, 940-950. [CrossRef]

46. Salimi, F.; Tahmasobi, K.; Karami, C.; Jahangiri, A. Preparation of modified nano-SiO 2 by bismuth and iron as a novel remover of methylene blue from water solution. J. Mex. Chem. Soc. 2017, 61, 250-259. [CrossRef]

47. Badr, Y.; Abd El-Wahed, M.G.; Mahmoud, M.A. Photocatalytic degradation of methyl red dye by silica nanoparticles. J. Hazard. Mater. 2008, 154, 245-253. [CrossRef]

48. Jadhav, S.A.; Garud, H.B.; Patil, A.H.; Patil, G.D.; Patil, C.R.; Dongale, T.D.; Patil, P.S. Recent advancements in silica nanoparticles based technologies for removal of dyes from water. Colloid Interface Sci. Commun. 2019, 30, 100181. [CrossRef]

49. Wang, X.; Han, S.; Zhang, Q.; Zhang, N.; Zhao, D. Photocatalytic oxidation degradation mechanism study of methylene blue dye waste water with GR/iTO 2 . In Proceedings of the MATEC Web of Conferences, Warsaw, Poland, 5-7 October 2017; EDP Sciences: Les Ulis, France, 2018; Volume 238, p. 3006. 